\title{
Uma revisão das técnicas de detecção molecular de Treponema pallidum, qual a mais
}

\section{eficaz}

\author{
A review of Treponema pallidum Molecular Detection Techniques, which is the most effective \\ Una revisión de las técnicas de detección molecular de Treponema pallidum, que es la más efectiva
}

Recebido: 20/07/2021 | Revisado: 26/07/2021 | Aceito: 27/07/2021 | Publicado: 03/08/2021

\author{
Vera Mileide Trivellato Grassi \\ ORCID: https://orcid.org/0000-0003-0987-5084 \\ Universidade Luterana do Brasil, Brasil \\ E-mail: vmgrassi@hotmail.com \\ Liliane Trivellato Grassi \\ ORCID: https://orcid.org/0000-0003-0768-943X \\ Universidade Brasil, Brasil \\ E-mail: lilianegrassi@hotmail.com \\ Maria Lucia Rosa Rossetti \\ Universidade Luterana do Brasil, Brasil \\ ORCID: https://orcid.org/0000-0002-9672-9394 \\ E-mail: maria.rossetti@ulbra.br
}

\begin{abstract}
Resumo:
A sífilis é uma doença polimórfica, infectocontagiosa e sistêmica, causada pela bactéria T. pallidum, considerada um agravo de notificação compulsória. O diagnóstico precoce é um fator importante no seu controle, este é realizado combinando achados clínicos e exames laboratoriais. As técnicas moleculares ajudam no diagnóstico, no entanto, não se tem um consenso sobre qual técnica é a mais adequada, estudos apresentam divergências como, qual gene deve ser usado como alvo, qual sequência dos primers, método de extração e tipo de amostra. Esta revisão procurou investigar com base nas evidências científicas, as técnicas moleculares mais eficazes na detecção de DNA de Treponema pallidum. Para tanto, realizou-se uma revisão sistemática da literatura realizada nas bases de dados PubMed, Science Direct e Lilacs, através dos descritores "sífilis" and "PCR and "diagnóstico" and "biologia molecular", selecionando trabalhos publicados nos últimos dez anos. A amostra foi composta por 10 artigos. Quanto ao desenho de estudo, o ensaio clínico foi $100 \%$ prevalente. Quanto ao método utilizado foi evidenciado variações, 6 utilizaram PCR Nested, 5 PCR em tempo real e 4 PCR convencional, 5 utilizam mais de uma variação. A diferença entre elas, como, tempo para avaliar uma reação, chance de contaminação, reprodutibilidade, especificidade, sensibilidade, precisão e acurácia diagnóstica, mostrou que os dois genes de maior interesse são o pol A e o tpp47. Os testes moleculares em especial o PCR nested demostrou ser promissor tendo boa sensibilidade e especificidade no diagnóstico da sífilis em conjunto com a sorologia para evitar complicações clínicas e transmissão da doença.
\end{abstract}

Palavras-chave: Sífilis; PCR; Diagnóstico; Biologia molecular.

\begin{abstract}
:
Syphilis is a polymorphic, infectious and systemic disease, caused by the bacteria T. pallidum, considered a disease of compulsory notification. Early diagnosis is an important factor in its control, this is performed by combining clinical findings and laboratory tests. Molecular techniques help in the diagnosis, however, there is no consensus on which technique would is the most appropriate, because studies present divergences such as which gene should be used as target, what sequence of primer, extraction method and type of sample. This review sought to investigate, based on scientific evidence, the most effective molecular techniques in the detection of T. pallidum DNA. Therefore, a systematic review of the literature was conducted in the PubMed, Science Direct and Lilacs databases, using the descriptors "syphilis" and "PCR" and "diagnosis" and "molecular biology", selecting works published in the last ten years. The sample consisted of 10 articles. As for the study design, the clinical trial was $100 \%$ prevalent. As for the method used, variations were evidenced, 6 used Nested PCR, 5 real-time PCR and 4 conventional PCR, 5 used more than one variation. The difference between them, such as time to evaluate a reaction, chance of contamination, reproducibility, specificity, sensitivity, precision and diagnostic accuracy, showed that the two genes of greatest interest are pol A and tpp47. Molecular tests, in particular nested PCR, proved to be promising, with good sensitivity and specificity in the diagnosis of syphilis together with serology to avoid clinical complications and disease transmission.
\end{abstract}

Keywords: Syphilis; PCR; Diagnosis; Molecular biology. 


\section{Resumen:}

La sífilis es una enfermedad polimórfica, infecciosa y sistémica, causada por la bacteria T. pallidum, considerada una enfermedad de notificación obligatoria. El diagnóstico precoz es un factor importante en su control, que se realiza combinando hallazgos clínicos y pruebas de laboratorio. Las técnicas moleculares ayudan en el diagnóstico, sin embargo, no existe consenso sobre qué técnica es la más adecuada, los estudios muestran divergencias como qué gen debe usarse como diana, qué secuencia de cebador, método de extracción y tipo de muestra. Esta revisión buscó investigar, con base en evidencia científica, las técnicas moleculares más efectivas para detectar el ADN de T. pallidum. Por ello, se realizó una revisión bibliográfica sistemática en las bases de datos PubMed, Science Direct y Lilacs, utilizando los descriptores "sífilis" y "PCR" y "diagnóstico" y "biología molecular", seleccionando trabajos publicados en los últimos diez años. La muestra estuvo formada por 10 artículos. En cuanto al diseño del estudio, el ensayo clínico tuvo una prevalencia del 100\%. En cuanto al método utilizado, se evidenciaron variaciones, 6 utilizaron PCR anidada, 5 PCR en tiempo real y 4 PCR convencional, 5 utilizaron más de una variación. La diferencia entre ellos, como el tiempo para evaluar una reacción, la probabilidad de contaminación, la reproducibilidad, la especificidad, la sensibilidad, la precisión y la exactitud diagnóstica, mostró que los dos genes de mayor interés son pol A y tpp47. Las pruebas moleculares, en particular la PCR anidada, demostraron ser prometedoras, tiniendo buena sensibilidad y especificidad en el diagnóstico de la sífilis junto con la serología para evitar complicaciones clínicas y la transmisión de la enfermedad.

Palabras clave: Sífilis; PCR; Diagnóstico; Biología Molecular.

\section{Introdução}

A sífilis adquirida é uma doença polimórfica, infectocontagiosa e sistêmica, causada pela bactéria Treponema pallidum subespécie pallidum. Suas principais vias de transmissão são a sexual e a vertical. Sinais clínicos comuns como as lesões cutaneomucosas das fases primária ou secundária, a sífilis adquirida pode acarretar manifestações graves e irreversíveis. Além das consequências diretas, há extensa evidência que a sífilis facilita o risco de transmissão do HIV, seja por representar um marcador de comportamentos de risco para sua transmissão, seja pelo aumento da transmissibilidade decorrente da quebra da barreira cutânea e da presença de células inflamatórias ao nível das lesões cutaneomucosas (Lafond \& Lukehart, 2006; Carlson \& Dabiri \& Cribier \& Sell, 2011; Cohen \& Klausner \& Engelman \& Philip, 2013; Taylor \& Li \& Skinner \& Mickey, 2014).

A Organização Mundial da Saúde (OMS), com base nos dados de prevalência de 2009 a 2016, estimou o total de 376,4 milhões de Infecções Sexualmente Transmissíveis (ISTs) curáveis, sendo que desses 6,3 milhões de casos eram de sífilis (WHO, 2020). No Boletim Epidemiológico de 2019, pode-se observar que a sífilis adquirida é considerada como agravo de notificação compulsória desde 2010, teve sua taxa de detecção aumentada de 59,1 casos (por 100.000 habitantes) em 2017, para 75,8 casos em 2018. A prevalência da doença em gestantes e seus desfechos desfavoráveis, baseadas em dados coletados em 97 países, é de aproximadamente 1,36 milhão de casos de mulheres que apresentaram sífilis ativa durante a gestação, sendo que, uma grande proporção delas não recebeu tratamento ou se recebeu, foi de maneira inadequada (Brasil, 2019, Korenromp et al., 2019)

O T. pallidum pertence ao gênero Treponema, da ordem das Spirochaetales que se subdivide em duas famílias: Spirochataceae e Leptospiraceae. A Família das Spirochataceae possui sete gêneros, mas apenas com três de interesse na medicina, o Treponema, a Borrelia e a Leptospira (Castro, 2004; Castro et al., 2009; Brasil, 2016). O T. pallidum é um microrganismo não cultivável o que impossibilita o seu isolamento e dificulta o diagnóstico laboratorial (Ageron et al., 2009). Assim, o diagnóstico da sífilis é realizado combinando achados clínicos e exames laboratoriais que variam conforme cada fase da doença (Brasil, 2016).

Os métodos mais utilizados para diagnóstico são divididos em métodos sorológicos também conhecidos como indiretos, baseados na detecção de anticorpos (métodos não treponêmicos e treponêmicos) e métodos diretos, baseados na detecção da bactéria como a Microscopia de Campo Escuro (MCO), a imunofluorescência direta e os testes moleculares (Brasil, 2015; Brasil, 2016; Castro et al., 2016; Pereira et al., 2019). 
Esta bactéria, tem um único cromossomo circular de $1.138 .006 \mathrm{pb}$, com 92,2\% do genoma que apresenta 1.041 sequências codificadoras e com um conteúdo de 52.8\% de C/G (Fraga \& Goldini, 2014). Os dois genes mais utilizados como alvo, para realizar o diagnóstico por biologia molecular são o pol A e o tpp47, que codificam a DNA polimerase e uma proteína de membrana envolvida na síntese da parede celular respectivamente (Liu \& Rodes \& Chen \& Steiner, 2001; Ageron et al., 2015, Theel \& Katz \& Pillay, 2020).

Nos últimos anos houve uma verdadeira explosão de novas técnicas para o diagnóstico de diversas patologias através da análise do Material Genético, e a biologia molecular está tendo cada vez mais um papel importante no diagnóstico. Atualmente, pode-se analisar sequências de DNA simultaneamente, ou seja, fazer um perfil dos genes de um tipo celular (Brischetto \& Gassiep \& Whiley \& Norton, 2018; Theel et al., 2020).

A técnica da Reação em Cadeia da Polimerase (PCR) é uma técnica muito usada, apesar de estar sendo aperfeiçoada a cada dia, existem várias metodologias, algumas são praticamente toda automatizada e pode ser realizada em Tempo Real. Esta PCR em tempo real é uma plataforma que diminui o tempo e os riscos de contaminações e ainda pode ser associada a outras técnicas (Theel et al., 2020; Lou \& Xie \& Liao, 2021).

No caso da sífilis, estudos sobre o T. pallidum são bem complexos, e ferramentas moleculares se tornam muito úteis para a determinação da diversidade e epidemiologia das infecções. Além de ter o potencial de aprimorar o tratamento clínico, os métodos de prevenção e controle também podem contribuir para o melhor entendimento sobre aquisição e transmissão da sífilis (Shukalek et al., 2021).

No entanto, ainda não se tem uma técnica padrão, existem vários artigos publicados que divergem sobre as diferentes técnicas moleculares, qual gene deve ser usado como alvo, hoje os principais são *tp0105, *tpp15, *tpp47 e *tp1016 e quais as sequências de primers para cada gene. Também não há consenso sobre quais os métodos de extração do DNA devem ser utilizados e sobre o tipo de amostra a ser utilizada. A quantidade de alvos utilizados tende a variar de 1 a 3 genes. A maior parte desses testes utilizam sequências iniciadoras para genes que codificam lipoproteínas de membranas, e visam as regiões geneticamente conservadas, os quais têm sido clonados e sequenciados (Castro, 2004; Ageron et al., 2015; Theel et al., 2020; Shukalek et al., 2021).

O presente trabalho tem como objetivo investigar com base nas evidências científicas, as técnicas moleculares mais eficazes na detecção de DNA de Treponema pallidum.

Para o alcance do objetivo proposto buscou-se identificar os métodos e os genes que são categóricos na detecção do DNA de Treponema pallidum e apresentar a sensibilidade e especificidade dos melhores métodos a fim de se conhecer o mais eficaz para o diagnóstico molecular da sífilis pois até o momento não se tem uma técnica padrão.

\section{Metodologia}

\subsection{Tipo de Estudo}

O presente estudo trata-se de uma revisão sistemática da literatura científica. Segundo Galvão \& Sawada \& Trevizan (2004) e Galvão \& Pereira (2014) este tipo de estudo é um dos muitos recursos metodológicos utilizados para integrar as informações de estudos independentes, realizados separadamente, sendo uma forma de sintetizar as informações disponíveis em dado momento, sobre uma questão específica, de forma objetiva e reproduzível, trabalham com a mesma base temática, uma vez que identifica, analisa e reúne dados sobre um determinado assunto.

\subsection{Etapas do Estudo}

\subsubsection{Problema}

Qual das variações na técnica de PCR é mais eficaz na detecção de DNA de Treponema pallidum? 


\subsubsection{Locais de busca}

\subsubsection{Seleção das fontes}

Para seleção e coleta de material bibliográfico a pesquisa foi conduzida nas bases de dados eletrônicas: Literatura Latino-Americana do Caribe em Ciências da Saúde (LILACS) e Scientific Electronic Library Online (SCIELO), US National Library of Medicine National Institutes of Health (PUBMED) e SCIENCE DIRECT. As buscas para a coleta de dados secundários, foram realizadas no período de junho de 2021.

\subsubsection{Definição dos descritores / Palavras-chaves / Strings}

A coleta de dados secundários, triagem e seleção do material bibliográfico foram realizadas por mais de dois pesquisadores, para evitar possíveis vieses de seleção. Foram eleitos artigos com relevância clínica e científica, usando o operador lógico "AND" para combinação dos descritores utilizados para rastreamento das publicações. Os campos utilizados para a pesquisa foram: título, resumo e assunto. Para literatura nacional foram utilizados os Descritores em Ciências da Saúde (DeCS) e para o internacional o Medical Subject Headings (MeSH). Os descritores utilizados respectivamente foram: DeCS: sífilis, PCR, diagnóstico e biologia molecular; MeSH: syphilis, PCR, diagnosis e molecular biology.

A combinação dos termos utilizados como DeCS e MeSH para busca dos artigos foram: a) Sífilis and PCR; b) Sífilis and biologia molecular; c) Sífilis and PCR and diagnostico; d) Sífilis and PCR and diagnóstico and biologia molecular; e) Syphilis and PCR; f) Syphilis and molecular biology; g) Syphilis and PCR and diagnosis; h) Syphilis and PCR and diagnosis and molecular biology.

\subsubsection{Critérios de inclusão e exclusão}

Para a seleção das fontes, foram considerados como critério de inclusão:

1. Artigos indexados nas bases de dados a partir dos descritores (DeCS): sífilis, PCR, diagnóstico e biologia molecular e MeSH: syphilis, PCR, diagnosis e molecular biology;

2. Foram selecionados os artigos publicados nos idiomas português, espanhol e inglês que dissertam sobre a patologia sífilis e as técnicas moleculares utilizadas;

3. Estudos disponíveis em texto completo e originais, publicados nos últimos dez anos.

Como critérios de exclusão foram: artigos que após a leitura e análise crítica não atendam a questão norteadora; artigos que não atendam o período estimado de busca de dados; publicações não disponíveis em texto completo; artigo em duplicidade, revisões e outros formatos (tese, manuais, protocolo etc.).

\subsubsection{Estratégia de busca e seleção e análise dos artigos}

Após a realização da estratégia de busca nas referidas bases de dados, foram encontrados 708 estudos por meio de uma leitura analítica dos títulos. Optou-se por não incluir artigos de revisão, teses, dissertações e monografias, buscando contemplar maior nível de evidência. Do total de artigos científicos, 40 artigos (LILACS), 35 artigos (SCIELO), 248 artigos (PUBMED) e 385 artigos (SCIENCE DIRECT). Após a discriminação dos qualitativos pelas bases de dados, foi feita uma análise do resumo, adequação ao tema da revisão, exclusão de artigos pagos ou de revisão, exclusão dos que não estavam no período selecionado e que não se enquadravam dentro dos descritores e foram então selecionados 48 artigos científicos. Após organização das ideias e leitura dos artigos na íntegra, a amostra final consistiu em 10 artigos científicos que atenderam aos critérios de elegibilidade propostos, sendo 8 da PUBMED, 1 da SCIENCE DIRECT e 1 da LILACS. O resumo do processo de coleta, análise e seleção dos artigos incluídos na amostra desta pesquisa segue apresentado na Figura 1. 
Todos os trabalhos escolhidos nesta etapa obtiveram ordem de importância conforme os critérios pré-determinados, na sequência foi realizada a sintetização dos resultados da pesquisa.

Figura 1 - Fluxograma de coleta, análise e seleção dos artigos para o desenvolvimento da pesquisa, Cáceres - Mato Grosso, Brasil, 2021.

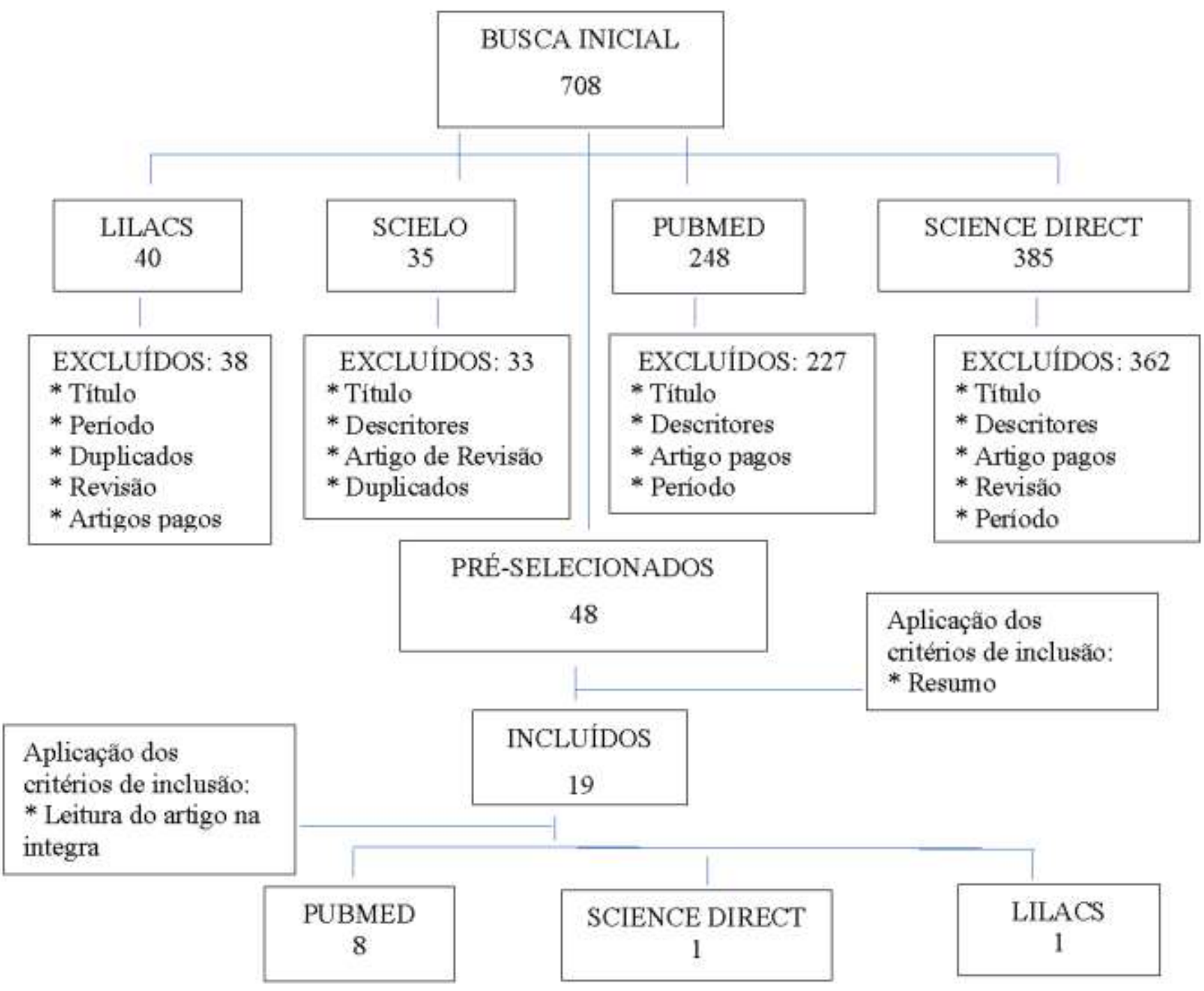

Fonte: Autores.

\section{Resultados e Discussão}

Na Tabela 1, está apresentado o perfil dos artigos selecionados para esta análise. O perfil descrito refere-se às variáveis: ano de publicação; revista/periódico; local da pesquisa e caracterização do delineamento/desenho de estudo. Conforme observado na Tabela 1 entre os dez artigos analisados, a PUBMED teve maior destaque como base de dados tendo $80 \%$ das publicações indexadas (Tabela 1).

Quanto ao desenho de estudo, todos os estudos selecionados eram de ensaio clínico, sendo 3 prospectivo, 2 retrospectivo e 1 observacional. Observou-se que, em relação ao qualis $70 \%$ são A e $20 \%$ B, mostrando excelente nível de qualidade nos artigos relacionados com objeto de pesquisa, somente 1 não possui qualis significativo. 
Quanto ao segmento temporal das publicações foi de 2012 a 2021, tendo os anos de 2019 e 2020 os maiores destaques (40\%) e os demais anos todos com apenas $10 \%$ de publicação cada. Ainda conforme dados da tabela 1, constatou-se que $40 \%$ das publicações foram originadas da França e China, e as demais publicações também são de fora do Brasil, mostrando que ainda temos muito que evoluir nas tecnologias moleculares.

Tabela 1 - Perfil dos artigos analisados segundo ano de publicação, autores, revista, base de dados, Qualis, local (Estado/região) e desenho de estudo, Cáceres-Mato Grosso, Brasil, 2021.

\begin{tabular}{|c|c|c|c|c|c|c|c|}
\hline $\mathbf{n}^{\mathbf{o}}$ & Ano & Autores & $\begin{array}{c}\text { Revista/Periódic } \\
\text { o }\end{array}$ & $\begin{array}{c}\text { Base de } \\
\text { dados }\end{array}$ & Qualis & País & Ensaio Clínico \\
\hline A1 & 2012 & Grange et al & $\begin{array}{l}\text { Journal of Clinical } \\
\text { Microbiology }\end{array}$ & PubMed & A2 & Paris - França & Prospectivo \\
\hline $\mathrm{A} 2$ & 2014 & Glatz et al & $\begin{array}{c}\text { Clinical } \\
\text { Microbiology and } \\
\text { Infection }\end{array}$ & $\begin{array}{l}\text { Sicenc } \\
\text { Ditect }\end{array}$ & A1 & Zurique - Suíça & Prospectivo \\
\hline A3 & 2015 & $\begin{array}{c}\text { Pinilla \& Chaverro } \\
\text { \& Moreno \& } \\
\text { Navarrete \& } \\
\text { Muñoz }\end{array}$ & Nova & Lilacs & & Bogotá- Colômbia & Ensaio clínico \\
\hline $\mathrm{A} 4$ & 2016 & Castro et al & $\begin{array}{c}\text { Journal of Clinical } \\
\text { Laboratory } \\
\text { Alalisis }\end{array}$ & PubMed & B1 & Lisboa - Portugal & Ensaio clínico \\
\hline A5 & 2018 & Wang et al & $\begin{array}{l}\text { Emerging } \\
\text { Microbes \& } \\
\text { Infections }\end{array}$ & PubMed & A1 & Shanghai - China & Ensaio clínico \\
\hline A6 & 2019 & $\begin{array}{l}\text { Noda \& Rodriguez } \\
\text { \& Grillová \& } \\
\text { Bosshard \& } \\
\text { Lienhard }\end{array}$ & $\begin{array}{c}\text { International } \\
\text { Journal of STD \& } \\
\text { AIDS }\end{array}$ & PubMed & B1 & Havana - Cuba & $\begin{array}{l}\text { Observacional / } \\
\text { Prospectivo }\end{array}$ \\
\hline A7 & 2019 & Zhang et al & $\begin{array}{l}\text { Sexually } \\
\text { Transmited } \\
\text { Diseases }\end{array}$ & PubMed & A4 & $\begin{array}{l}\text { Guangzhou - } \\
\text { China }\end{array}$ & Ensaio clínico \\
\hline A8 & 2020 & Grange et al & $\begin{array}{c}\text { Journal Of } \\
\text { Clinical } \\
\text { Microbiology }\end{array}$ & PubMed & A2 & Paris - França & Ensaio clínico \\
\hline A9 & 2020 & Vrbova et al & Plos One & PubMed & A1 & $\begin{array}{c}\text { Brno - República } \\
\text { Tcheca }\end{array}$ & Retrospectivo \\
\hline A10 & 2021 & Shukalek et al & $\begin{array}{l}\text { Frontier in } \\
\text { Cellular and } \\
\text { Infection } \\
\text { Microbiology }\end{array}$ & PubMed & A1 & Alberta - Canadá & Retrospectivo \\
\hline
\end{tabular}

Fonte: Autores.

Comparando os anos de 2012 a 2021, notou-se um aumento dos números de pesquisas relacionadas às técnicas moleculares na detecção de DNA. De 2012 a 2019 havia mais estudos prospectivos, onde se trabalhava com o desfecho que ainda não ocorreu, quando comparado ao ano de 2020, que demonstra uma mudança passando a estudar o paciente a partir de um desfecho, o que enfatiza a credibilidade nos dados de registros do passado, em relação a exposição do fator e/ou a sua intensidade.

Na Tabela 2, foram incluídas as particularidades dos estudos referente ao método utilizado nas pesquisas, o públicoalvo do estudo, o método de coleta, os genes utilizados e o principal desfecho. 
Research, Society and Development, v. 10, n. 9, e59310918478, 2021

(CC BY 4.0) | ISSN 2525-3409 | DOI: http://dx.doi.org/10.33448/rsd-v10i9.18478

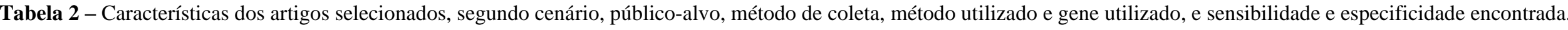

\begin{tabular}{|c|c|c|c|c|c|c|}
\hline $\mathrm{n}^{\mathbf{0}}$ & Cenário & Público-alvo & Tipo de Amostra & Método Utilizado & Gene Utilizado & Desfecho \\
\hline A1 & $\begin{array}{c}\text { Dois centros de DST em Paris - } \\
\text { França }\end{array}$ & $\begin{array}{l}\text { População com } \\
\text { suspeita de sífilis e } \\
\text { indivíduos } \\
\text { saudáveis }\end{array}$ & $\begin{array}{l}\text { Swabs de lesão, soro, } \\
\text { plasma e sangue total }\end{array}$ & Neste PCR & $\begin{array}{l}\text { Gene tpp47- } \\
\text { mas usou dois } \\
\text { pares de primers } \\
\text { KO5 e KO3B e } \\
\text { o Tpe e Tps }\end{array}$ & $\begin{array}{c}\text { Em Swabs } 82 \% \text { sensibilidade e } \\
\text { 95\% especificidade } \\
\text { Em plasma (18 e } 92) \text {, soro }(14,7 \text { e } 93) \\
\text { e sangue total (24 e } 97)\end{array}$ \\
\hline $\mathrm{A} 2$ & $\begin{array}{c}\text { Departamento de Dermatologia, do } \\
\text { Hospital Universitário de Zurique } \\
\text { (Suíça) }\end{array}$ & $\begin{array}{l}\text { População adulta } \\
\text { com úlceras na } \\
\text { região genital }\end{array}$ & $\begin{array}{l}\text { Swabs de úlceras } \\
\text { genitais, anais e } \\
\text { orofaríngea }\end{array}$ & $\begin{array}{l}\text { PCR em tempo real } \\
\text { comparado com } \\
\text { Sorologia e } \\
\text { Microscopia de } \\
\text { campo escuro } \\
\end{array}$ & $\begin{array}{l}\text { Primers } \\
\text { desenhados para } \\
\text { o gene } 16 S \\
\text { rRNA }\end{array}$ & $\begin{array}{l}100 \% \text { Sensibilidade } \\
100 \% \text { especificidade }\end{array}$ \\
\hline A3 & $\begin{array}{l}\text { Departamento de Imunopatologia da } \\
\text { Sífilis da Universidade de Washington }\end{array}$ & Recém-nascidos & Cordão Umbilical & $\begin{array}{l}\text { PCR Convencional, } \\
\text { PCR Nested, e PCR } \\
\text { em tempo real }\end{array}$ & $\begin{array}{c}\text { pol } A, 16 S \\
r D N A, t p N 47\end{array}$ & $\begin{array}{l}\text { Alvo tpN47 teve melhor sensibilidade } \\
\text { e especificidade que os outros }\end{array}$ \\
\hline A4 & Instituto de Higiene e medicina Tropical & $\begin{array}{l}\text { População com } \\
\text { amostras positivas } \\
\text { para sífilis }\end{array}$ & LCR & PCR convencional & pol A e tpp47 & $\begin{array}{c}\text { Mostrou que o tpp47 é mais sensível } \\
\text { (75,8\% vs } 69,7 \% \text { do pol } A \text { ), é o pol } A \\
\text { foi mais específico } 92,3 \% \text { vs } 86,8 \text { do } \\
\text { tpp } 47\end{array}$ \\
\hline A5 & $\begin{array}{c}\text { Clínica de Doenças Sexualmente } \\
\text { Transmissíveis do Hospital de Doenças } \\
\text { da Pele de Shanghai }\end{array}$ & $\begin{array}{l}\text { População em } \\
\text { diferentes estágios } \\
\text { da sífilis }\end{array}$ & Sangue total & $\begin{array}{l}\text { PCR convencional e } \\
\text { PCR Nested }\end{array}$ & pol $A$ e tpp 47 & $\begin{array}{l}228 \text { amostras concordaram entre os } \\
\text { PCR Nested dos dois genes. Mas a } \\
\text { detecção foi muito baixa na sífilis } \\
\text { latente }\end{array}$ \\
\hline A6 & $\begin{array}{c}\text { Instituto de Medicina Tropical "Pedro } \\
\text { Kouri" (IPK) - Havana, Cuba }\end{array}$ & $\begin{array}{l}\text { População com } \\
\text { úlceras ano genitais }\end{array}$ & $\begin{array}{l}\text { Swab de úlceras anais e } \\
\text { genitais }\end{array}$ & $\begin{array}{l}3 \text { PCR em tempo } \\
\text { real, } 1 \text { para cada gene }\end{array}$ & $\begin{array}{c}\text { pol } A, \text { tpp47 e } \\
16 S \text { rDNA }\end{array}$ & $\begin{array}{l}\text { Comparou os três PCR com os } \\
\text { exames sorológicos. Concordância } \\
\text { entre sorologia e PCR foi de } 52,3 \text {. }\end{array}$ \\
\hline A7 & $\begin{array}{c}\text { Departamento ambulatorial de } \\
\text { dermatologia ou doenças sexualmente } \\
\text { transmissíveis de sete hospitais em } \\
\text { Guangzhou - China }\end{array}$ & $\begin{array}{l}\text { População com } \\
\text { suspeita de sífilis de } \\
\text { qualquer fase e um } \\
\text { grupo controle }\end{array}$ & $\begin{array}{c}\text { Swabs de Úlcera, } \\
\text { sangue total, LCR, soro } \\
\text { e sangue do lóbulo da } \\
\text { orelha }\end{array}$ & $\begin{array}{l}\text { PCR Nested em } \\
\text { tempo Real }\end{array}$ & $\begin{array}{l}\text { pol A Novos } \\
\text { primers }\end{array}$ & $\begin{array}{l}\text { Detectou } 71,7 \% \text { das amostras } \\
\text { positivas para sífilis. Todas as } \\
\text { amostras controles foram negativas. }\end{array}$ \\
\hline A8 & $\begin{array}{c}\text { Em seis Centros } \\
\text { de DST na França. Centro de Referência } \\
\text { Nacional para DSTs bacterianas no } \\
\text { Hospital Cochin em Paris }\end{array}$ & $\begin{array}{l}\text { População com } \\
\text { úlceras genitais }\end{array}$ & $\begin{array}{l}\text { Swabs de úlceras } \\
\text { genitais }\end{array}$ & $\begin{array}{c}\text { Kit comercial Alplex } \\
\text { (PCR em tempo real } \\
\text { para } 7 \text { ISTs) } \\
\text { PCR Nested para } \\
\text { Treponema } \\
\end{array}$ & $\begin{array}{c}\text { tpp47 (primers } \\
\text { Ko5 e Ko3B) e } \\
\text { TPA (primers } \\
\text { Tpe e Tps) }\end{array}$ & $\begin{array}{c}\text { Quando comparados os dois testes } \\
\text { PCR com diagnósticos sorológicos e } \\
\text { clínicos da sífilis, obteve } 80 \% \text { de } \\
\text { sensibilidade, } 98.8 \% \text { especificidade e } \\
\text { Kappa }=0,85\end{array}$ \\
\hline A9 & $\begin{array}{l}\text { Departamento Dermatovenerologia } \\
\text { (Hospital da Faculdade St. Anne); }\end{array}$ & $\begin{array}{l}\text { População suspeita } \\
\text { de sífilis }\end{array}$ & $\begin{array}{l}\text { Swabs de úlceras } \\
\text { cutâneas, úlceras }\end{array}$ & $\begin{array}{l}\text { PCR Nested, com } \\
\text { touchdown }\end{array}$ & $\begin{array}{l}\text { Alvos: TP0136, } \\
\text { TP0548, }\end{array}$ & $\begin{array}{c}\text { Sensibilidade de } 72,3 \% \text { e } \\
\text { especificidade de } 100 \% \text { comparada }\end{array}$ \\
\hline
\end{tabular}


Research, Society and Development, v. 10, n. 9, e59310918478, 2021

(CC BY 4.0) | ISSN 2525-3409 | DOI: http://dx.doi.org/10.33448/rsd-v10i9.18478

\begin{tabular}{|c|c|c|c|c|c|c|}
\hline & $\begin{array}{c}\text { Departamento Dermatovenerologia } \\
\text { (Hospital da Faculdade Brno, } \\
\text { Universidade de Masaryk); } \\
\text { Departamento Dermatovenerologia } \\
\text { (Universidade Charles) e Laboratório de } \\
\text { Referência Nacional para Diagnóstico de } \\
\text { Sífilis (Instituto Nacional de Saúde } \\
\text { Pública) }\end{array}$ & & $\begin{array}{l}\text { orofaríngeas, úlceras } \\
\text { ano genitais, úlceras } \\
\text { sem localização, } \\
\text { sangue total }\end{array}$ & & $\begin{array}{c}\text { TP0705, } \\
\text { 23SrDNA, } \\
\text { TP0319 }(\mathrm{t} m p \mathrm{C}) \\
\text { TP0105(pol } A)\end{array}$ & com o diagnóstico do CDC. \\
\hline A10 & $\begin{array}{l}\text { Dois grandes centros especialistas em } \\
\text { DST de Alberta - Canada }\end{array}$ & $\begin{array}{c}\text { População adulta } \\
\text { com lesões ano } \\
\text { genitais }\end{array}$ & Lesões ano genitais & PCR & $p o l$ A e tpp47 & $\begin{array}{c}\text { Encontrou sensibilidade de } 49,3 \mathrm{e} \\
\text { especificidade de } 99,9\end{array}$ \\
\hline
\end{tabular}

Fonte: Autores. 
A partir da análise das informações obtidas, foi possível identificar que os dois genes de maior interesse para realizar o diagnóstico de T. pallidum por biologia molecular são o pol A e o tpp47. Nota-se que estes são os dois genes mais utilizados, embora exista outros genes alternativos usados com menos frequência, por exemplo o $16 \mathrm{~S}$ rDNA e TP0319 (tmpC). O pol A codifica a DNA polimerase I que está relacionada com o reparo e replicação do DNA e o tpp47 codifica uma proteína de membrana citoplasmática envolvida na síntese da parede celular, ambos os genes estão presentes nos genomas de T. pallidum (Ageron et al., 2015).

Dos artigos selecionados os estudos A1, A3, A4, A5, A6, A8 e A10 defendem a utilização do gene tpp47, enquanto nos estudos A3, A4, A5, A6, A7 e A10 fazem uso do gene pol A e poucos estudos (A2, A3 e A6) fazem uso do gene $16 \mathrm{~S}$ rDNA, e apenas um estudo o A9 faz uso do TP0319. No entanto, observa-se que a maioria dos estudos utilizam mais de um gene, isto ocorre devido a uma não padronização da técnica.

O estudo A1 usou o PCR Nested especificamente para gene tpp47 de T. pallidum utilizando amostra de sangue total, plasma, soro e swabs de lesão, em 294 pacientes com suspeita de sífilis e 35 voluntários saudáveis. As análises de amostras de swabs de lesão de pacientes com diagnóstico de sífilis e de pacientes sem sífilis tiveram boa sensibilidade (82\%) e especificidade (95\%) para a detecção do genoma de T. pallidum em pacientes com sífilis primária e secundária. Já no sangue total o genoma do T. pallidum apresentou uma baixa sensibilidade de $24 \%$, mas uma boa especificidade (97\%), o mesmo ocorreu com o plasma e o soro sensibilidade de 18 e 14,7 e especificidade de 92 e 93 respectivamente. Esta diferença na sensibilidade pode resultar do uso de um gene alvo diferente tpp 47 versus pol $A$ e as condições em que o sangue total foi armazenado, pois já foi demonstrado que o congelamento das amostras pode afetar a sensibilidade.

$\mathrm{O}$ estudo A2 avaliou diferentes amostras (swabs de úlceras genitais, anais e orofaríngeas) de pacientes com suspeita de sífilis, buscando a deteç̧ão do T. pallidum, utilizou o PCR em tempo real comparando com microscopia em campo escuro e sorologia, o gene pesquisado foi o $16 \mathrm{~S} r R N A$, observou-se que a sensibilidade e especificidade do PCR em tempo real foi de $100 \%$ para T. pallidum, quando comparado ao teste referência que é a microscopia de campo escuro. O PCR parece superior à sorologia nas infecções iniciais por T. pallidum.

Na pesquisa A3 os alvos moleculares (pol A, $16 \mathrm{~S} r D N A$, tpN47) de microrganismo foram amplificados por meio de PCR convencional, PCR Nested e PCR em tempo real em amostras de cordão umbilical de recém-nascido. Os três genes apresentam resultados semelhantes por PCR convencional; no caso de PCR nested e PCR em tempo real, o gene tpN47 exibiu maior sensibilidade e especificidade em comparação aos genes pol $A$ e $16 S r D N A$, mostrando que o gene tpN47 pode ser utilizado como alvo molecular para o diagnóstico imediato da sífilis congênita. Corroborando com o estudo acima Grange et al. (2012) utilizou o gene tpN47 para o diagnóstico de Neurosífilis (SN) no LCR, em comparação com os testes diagnósticos estabelecidos pela Organização Mundial da Saúde (OMS), onde comprovou a capacidade do microrganismo de invadir o SNC durante os estágios primários da doença.

Estudo feito com o gene tpN47, deu origem a resultados promissores e assim desenvolveu um qPCR para detectar $T$. pallidum subsp. pallidum sem reatividade cruzada com treponemas da flora comum da pele ou com patógenos associados a infecções sexualmente transmissíveis (ISTs), para ser usado para detectar e quantificar o microrganismo em diferentes lesões e estágios da doença, constatando que na sífilis primária existe um grande número de microrganismos nas úlceras, mas um número baixo de cópias no sangue; na sífilis secundária ocorre aumento da bacteremia, enquanto na fase latente a bacteremia e a carga treponêmica são detectadas com menor frequência (Tipple et al.,2011).

Em A4 os pesquisadores realizaram duas técnicas de reação em cadeia da polimerase (PCR) uma para cada gene (pol A e tpp47), para a detecção de DNA de T. pallidum no líquido cefalorraquidiano (LCR) de pacientes com sífilis. Mostrou que o tpp47 é mais sensível (75,8\% vs $69,7 \%$ do polA) e o pol A foi mais específico $92,3 \%$ vs 86,8 do tpp47. Porém ainda há 
dificuldades de se determinar qual é a melhor técnica a ser usada pois os resultados variam de acordo com o estágio da sífilis em especial na sífilis latente.

Além disso, o estudo A5 investigou o método PCR nested e o PCR convencional para os genes (pol A e tpp47) em amostras de sangue total de pacientes com diferentes fases da sífilis (primária, secundária e latente). O ensaio de PCR nested com os dois alvos (pol A e tpp47), detectou DNA T. pallidum em 53,6\% e 62,9\% dos pacientes com sífilis primária e secundária, respectivamente, o que foi muito superior aos níveis de detecção em pacientes com sífilis latente $(7,4 \%)$. Indicando que o PCR nested é um método sensível para detectar DNA T. pallidum no sangue, especialmente em pacientes com sífilis primária e sífilis secundária. A pesquisa feita por A4 vem amparar o estudo A5, quanto ao benefício do PCR utilizando dois genes alvos (pol A e tpp47) para detecção de DNA de T. pallidum em pacientes com sífilis primária e secundária.

Até o momento, nenhum gene específico foi recomendado como um alvo padrão-ouro para PCR do T. pallidum. No entanto, os genes tpp47 e pol A são os alvos mais promissores atualmente.

A6 avaliou o desempenho de 3 PCR uma para cada gene (pol A, tpp47 e $16 \mathrm{~S} \mathrm{rDNA}$ ) e o teste sorológico de pacientes adultos com úlceras ano genitais. Os testes moleculares e a sorologia não se correlacionaram bem, obteve concordância de 52,3\%. As sensibilidades dos ensaios de PCR (pol A, tpp47 e $16 \mathrm{~S} r D N A$ ) e sorologia (VDRL) foram 71,6\%, 57,5\%, 57,5\% e $67,2 \%$ e especificidade de $100 \%, 100 \%, 100 \%$ e $86,4 \%$ respectivamente. A combinação de PCR e sorologia pode oferecer informações valiosas para o diagnóstico de sífilis em pacientes que apresentam úlcera ano genital, evitando complicações clínicas adicionais e transmissão da doença.

Isto está em contraste com o estudo de Brischeto et al. (2018), que afirma que o PCR para detectar T. pallidum acrescenta pouco valor clínico sobre a sorologia e para o diagnóstico de sífilis em determinados contextos clínicos. Em seu estudo mostraram que a maioria dos pacientes com PCR positivo para o T. pallidum também tiverem resultado positivo na sorologia para sífilis.

O estudo A7 investigou a viabilidade do PCR nested (dois pares de primers para o gene pol A) para identificar DNA de T. pallidum em diferentes amostras (Swabs de úlcera, sangue total, LCR, soro e sangue do lóbulo da orelha) de pacientes com sífilis em qualquer fase. Entre os tipos de sífilis, a maioria das amostras testadas com PCR nested mostrou resultado positivo para 71,7\%, incluindo sangue do lóbulo da orelha (92,0\%), líquido cefalorraquidiano (LCR) (90,2\%), esfregaços de lesão $(74,3 \%)$, soro $(66,9 \%)$ e sangue total $(64,2 \%)$. Não foram observadas diferenças significativas em amostras positivas para sangue total, soro e esfregaços de lesão entre a sífilis primária e secundária, porém houve diferença entre sífilis terciaria, latente e neurosífilis. O PCR nested pode ser usado para identificar o DNA de T. pallidum de diferentes amostras de pacientes sifilíticos, mas a limitações como diferentes tamanhos de amostras.

Em outro estudo, A8 analisou o desempenho de duas técnicas, um novo ensaio PCR em tempo real comercial comparando com o ensaio de PCR nested, o DNA foi extraído de esfregaços genitais e mucosos coletados de pacientes com lesões mucocutâneas. O PCR em tempo real detectou o T. pallidum com uma sensibilidade de $80 \%$ e uma especificidade de 98,8\%. Em comparação com o ensaio de PCR nested (tpp47) que teve uma sensibilidade de $84 \%$ e uma especificidade de $100 \%$, a concordância entre os dois ensaios foi muito boa (92,5\%). A sensibilidade dependeu da localização da lesão. Este resultado foi comparado com o padrão ouro, ou seja, diagnóstico final de sífilis com base no exame clínico e testes sorológicos. Mostrou que o ensaio PCR em tempo real é adequado para detectar T. pallidum em uso de rotina e facilita a detecção rápida simultânea de patógenos relevantes em um contexto de lesões suspeitas de sífilis. As análises feitas pelos estudos A4 e A5 corroboram com a pesquisa mostrando que a PCR nested é relevante para deteç̧ão da sífilis pois mostrou uma boa sensibilidade e especificidade.

A análise do estudo A9 foi realizada em população suspeita de sífilis em diferentes amostras, swabs de úlceras cutâneas, úlceras orofaríngeas, úlceras ano genitais, úlceras sem localização e sangue total, comparando com os métodos 
sorológicos (não treponêmicos - RPR e treponêmicos - TPPA, ELISA e análise de Western Blot (WB) de IgM e IgG e com DNA de PCR usando alvos TP0136, TP0548, TP0705, genes 23SrRNA, TP0319 (tmpC) e TP0105 (pol A). Houve concordância de 59,6\% entre os testes de sorologia e PCR para todo o conjunto de amostras. A Sensibilidade, especificidade para a sorologia foi de $89,3 \%$ e $100 \%$ e para PCR $72,3 \%$ e $100 \%$ respectivamente.

Esses resultados são comparáveis com os resultados relatados por Noda et al (2019), os dados revelaram que PCR e sorologia não se correlacionaram bem (concordância $=52,3 \%$ ), mostrou que a combinação de PCR e sorologia pode oferecer informações valiosas para o diagnóstico de sífilis, evitando complicações clínicas adicionais e transmissão da doença.

Por fim, o resultado do estudo A10 realizado em população adulta de pacientes com lesões ano genitais, utilizando o método PCR e dois genes alvos diferentes ( $p o l$ A, tpp47) versus sorologia, mostrou que a PCR apresentou sensibilidade de 49,3\% e especificidade de $99,9 \%$. Apesar da baixa sensibilidade do teste molecular para sífilis primária este é um teste altamente específico e útil na confirmação do diagnóstico e poderia ser utilizado não como um teste de triagem, mas sim utilizar os testes de sorologias simultâneos com o PCR pois poderiam garantir que todos os casos sejam identificados para gerenciar o agravamento da epidemia. O estudo A9 contribui com o estudo mostrando que a PCR é vantajosa na confirmação do diagnóstico de sífilis e assim evitar a sua transmissão.

\section{Considerações Finais}

Em uma análise geral dos artigos, observam-se variações da mesma técnica, com a utilização de genes alvos e material de amostra diferenciado, o que demonstra que a pesquisa na biologia molecular tem evoluído e que os pesquisadores estão tentando padronizar um método mais adequado, válido para o diagnóstico de sífilis.

No que se refere aos genes mais empregados como alvo, destacam-se o pol A e o tpp47 estes por serem de regiões conservadas no genoma do T. pallidum, dessa maneira, apresentam melhor aplicabilidade no diagnóstico da sífilis.

Em relação aos testes moleculares o ensaio PCR nested demonstrou ser promissor tendo boa sensibilidade e especificidade no diagnóstico da sífilis primária e secundária em conjunto com a sorologia para evitar complicações clínicas e transmissão da doença, dessa forma impedir o agravamento da epidemia.

\section{Referências}

Ageron, A G., Laurent, F., Schrenzel. J., Charton, B., Getaz, G. J., Tangomo, M., Tristan, B., Sednaoui, P., Lautenschlager, S., Trellu, LT., Tejada, B. M., Cavassini, M., Emonet, S., Perneger, T., Salord H. (2015). Perfonmance of the 47 kilodalton menbrane protein versus DNA Polymerase I genes for detection of Treponema pallidum by PCRin ulcers. Journal of Clinical Microbiology. Mar;53(3):976-80. DOI: 10.1128/JCM.03444-14

Ageron, A. G., Ninet, B., Trellu, L. T., Lautenschlager, S., Furrer, H., Piguet, V., Schrenzel, J., Hirschel, B. (2009). Assessment of a Real Time PCR to Diagnose Syphilis fron deversi biologicalsample. Sexually Transmitted Infections. Ago;85(4):264-9. DOI: 10.1136/sti.2008.034314

Brasil, M.d.S. (2016). Manual Técnico para o Diagnóstico da Sífilis. - PNCQ.

Brasil, M.d.S. (2019).Boletim Epidemiológico da Sífilis.

Brasil, M. D. S. (2015). Protocolo Clínico e Diretrizes Terapêuticas para Atenção Integral às Pessoas com Infecção Sexual Tranmissivel.

Brischetto, A., Gassiep, I., Whiley, D., Norton, R. (2018). Retrospective review of Treponema pallidum PCR and serology results: are both tests necessary? Journal of Clinical Microbiology. p.1-7, v.56 n.5. 56:e01782-17. DOI: 10.1128/JCM.01782-17.

Carlson, JA., Dabiri, G., Cribier, Sell, S. (2011). The immunopathobiology of syphilis: the manifestations and course of syphilis are determined by the level of delayed-type hypersensitivity. The American Journal of Dermatopathology. Jul;33(5):433-460. DOI: 10.1097/dad.0b013e3181e8b587

Castro MRTd. (2004). Contribuição para o estudo da infeçãopor Treponema pallidum subespecie pallidum: Resposta sorologica, Diagnsotico Molecular e Genotipagem. Dissertação de Doutorado. Lisboa - Portugal (LISBOA): Universidade Nova Lisboa.

Castro, R., Águas, M. J., Batista, T., Araújo, C., Mansinho, K., Pereira, FdaL. (2016). Detection of Treponema pallidum Sp. Pallidum DNA in Cerebrospinal Fluid (CSF) by Two PCR Techniques. Journal of Clinical Laboratory Analysis. Sep;30(5):628-32. DOI: 10.1002/jcla.21913. Epub 2016 Feb 18. PMID: 26892231; PMCID: PMC6807054.

Castro, R., Prieto, E., Aguas, M. J., Manata, M. J., Botas, J., Pereira F. M. (2009). Molecular subtyping of Treponema pallidum subsp. pallidum in Lisbon, 
Portugal. Journal of Clinical Microbiology. Aug;47(8):2510-2. DOI: 10.1128/JCM.00287-08. Epub 2009 Jun 3. PMID: 19494073; PMCID: PMC2725690.

Cohen, S. E., Klausner, J. D., Engelman, J., Philip, S. (2013). Syphilis in the modern era: an update for physicians. Infectious Disease Clinics of North America. Dec;27(4):705-22. DOI: 10.1016/j.idc.2013.08.005. PMID: 24275265.

Fraga, D. D. ., \& Goldini, L. Z. (2013). Detecção do Treponema pallidum em Liquido Cefalorraquidiano LCR pela reação em cadeia de polimerase PCR em pacientes HIV positivos assintomaticos com diagnsotico de sífilis latente. Dissertação para titulo de Mestre. Porto Alegre: Universidade Federal do Rio Grande do Sul.

Galvão, C. M., Sawada, N. O., Trevizan, M. A. (2004). Revisão Sistemática: Recurso que proporciona a incorporação das evidências na prática da enfermagem. Revista Latino-americano Enfermagem, 12(3):549-56. DOI:10.1590/S0104-11692004000300014

Galvão, T. F., Pereira, M. G. (2014). Revisões sistemáticas da literatura: passos para sua elaboração. Epidemiologia e. Serviços de Saúde. 23 (1):183-184. DOI: $10.5123 /$ S1679-49742014000100018.

Glatz, M., Juricevic, N. Altwegg, M., Bruisten, S., Komericki, P., Lautenschlager, S., Weber, R., Bosshard, P. P. (2014). A multicenter prospective trial to asses a new real-time polymerase chain reaction for detection of Treponema pallidum, herpes simplex-1/2 and Haemophilus ducreyi in genital, anal and oropharyngeal ulcers. Clinical Microbiology Infection. Dec;20(12):O1020-7. DOI: 10.1111/1469-0691.12710. Epub 2014 Jul 25. PMID: 24909546.

Grange, P. A., Gressier, L., Dion, P. L., Farhi, D., Benhaddou, N., Gerhardt, P., Morini, J. P., Deleuze, J., Pantoja, C., Bianchi, A., Lassau, F., Avril, M. F., Janier, M., Dupin, N. (2012). Evaluation of a PCR test for detection of treponema pallidum in swabs and blood. Journal of Clinical Microbiology. Mar;50(3):546-52. DOI: 10.1128/JCM.00702-11. Epub 2012 Jan 4. PMID: 22219306; PMCID: PMC3295187.

Grange, P. A., Jary, A., Isnard, C., Burrel, S., Boutolleau, D., Touati, A., Bébéar, C., Saule, J., Martinet, P., Robert, J. L., Moulene, D., Vermersch-Langlin, A., Benhaddou, N., Janier, M., Dupin, N. (2021). Use of a Multiplex PCR Assay To Assess the Presence of Treponema pallidum in Mucocutaneous Ulcerations in Patients with Suspected Syphilis. Journal of Clinical Microbiology. Jan 21;59(2):e01994-20. doi: 10.1128/JCM.01994-20. PMID: 33177120; PMCID: PMC8111117.

Korenromp, E. L., Rowley, J., Alonso, M., Mello, MB., Wijesooriya, N. S.,7 Mahiné, SG., Ishikawa, N., Le, L. V., Newman-Owiredu, N., Nagelkerke, N., Newman, L., Kamb, M.,7 Broutet, N., Taylor, M. M. (2019). Global burden of maternal and congenital syphilis and associated adverse birth outcomesEstimates for 2016 and progress since 2012 journal.pone.0211720. PLoS One. 14(7):1-17. DOI:10.1371/journal.pone.0219613.

Lafond, R. E., Lukehart, S. A. (2006). Biological basis for syphilis. Clinical Microbiology Reviews. Jan;19(1):29-49. DOI: 10.1128/CMR.19.1.29-49.2006. PMID: 16418521; PMCID: PMC1360276.

Liu, H., Rodes, B. Chen, C. Y., Steiner, B. (2001). New tests for syphilis: rational design of a PCR method for detection of Treponema pallidum in clinical specimens using unique regions of the DNA polymerase I gene. Journal of Clinical Microbiology. May;39(5):1941-6. DOI: 10.1128/JCM.39.5.19411946.2001. PMID: 11326018; PMCID: PMC88053.

Luo, Y., Xie, Y., Xiao, Y. (2021).Laboratory diagnostic tools for syphilis: Current status and future prospcts. Frontiers in cellular and infection microbiology. 8 de fevereiro de 2021;10:574806. DOI: 10.3389/fcimb.2020.574806. 33628742; PMCID: PMC7897658.

Noda, A. A., Rodríguez, I., Grillová, L., Bosshard, P. P., Lienhard, R. (2019). Accuracy of PCR and serological testing for the diagnosis of primary syphilis: Both tests are necessary. International Journal of STD \& AIDS. 30: 1087-1094. DOI:10.1177/0956462419859764

Pereira, J. B.,7 Barbosa Júnior, W. L., Silva, E. D., Aquino, A. E. C. A., Oliveira, P. M. S., Melo, FL. (2019). Comparação de técnicas de extração de DNA de Treponema Pallidum para o diagnóstico molecular da sífilis. Brazilian Journal of Health Review. Curitiba, v. 2, n. 4, p. 3681-3697. DOI:10.34119/bjhrv2n4131

Pinilla, G. B., Chavarro, B. P., \& Moreno, M. A., Navarrete, J. O., Muñoz, L. M. (2015). Determinación de los genes, 16S ADNr, polA, y TpN47, em la detección de Treponema pallidum subsp. pallidum para el diagnóstico de sífilis congénita. NOVA. 13 (23): 17-25.

Shukalek, C. B., Lee, B., Fathima, S., Chu, A., Fonseca, K.,7 Somayaji, R. (2021). Comparative Analysis of Molecular and Serologic Testing for Primary Syphilis: A Population-Based Cohort Study. Frontiers in Cellular and. Infection Microbiology. 11:579660. DOI: 10.3389/fcimb.2021.579660

Taylor, M. M., Li, W. Y., Skinner, J., Mickey, T. (2014). Viral loads among young HIV-infected men with early syphilis. Journal of the International Association Providers AIDS Care. Nov-Dec;13(6):501-5. DOI: 10.1177/2325957414536229. Epub 2014 Jun 4. PMID: 24899260; PMCID: PMC6754093.

Theel, E. S., Katz, S. S., Pillay, A. (2020). Molecular and direct detection Testes for Treponema pallidum subspecies pallidum: A review of the literature, 1964-2017. Clinical Infectious Diseases. Jun 24;71(Suppl 1):S4-S12. DOI: 10.1093/cid/ciaa176. 32578865; PMCID: PMC7312206.

Tipple, C., Hanna, M. O. F., Hill, S., Daniel, J., Goldmeie, D., McClure, M., Taylor, G. P. (2011). Getting the measure of syphilis: qPCR to better understand early infection. Sexually Transmited Infections p. 479-485, v. 87, n.6. DOI:10.1136/sti.2011.049494

Vrbová, E., Mikalová, L., Grillová, L., Pospíšilová, P., Strnadel, R., Dastychová, E., Kojanová, M., Kreidlová, M., Vaěousová, D., Rob, F.,\& Procházka, P., Krchěáková, A., Vaška, V., Woznicová, V., Dvoř́áková Herová, M., Kuklová, I., Zákoucká, H., Šmajs, D. (2020). A retrospective study on nested PCR detection of syphilis treponemes in clinical samples: PCR detection contributes to the diagnosis of syphilis in patients with seronegative and serodiscrepant results. PLos One. Ago 20;15(8):e0237949. DOI: 10.1371/journal.pone.0237949. 32817658; PMCID: PMC7446855.

Wang, C., Cheng, Y.,\& Liu, B., Wang, Y., Gong, W., Qian, Y., Guan, Z., Lu, H.,\& Gu. X., Shi, M., Zhou, P. (2018). Sensitive detection of Treponema pallidum DNA from the whole blood of patients with syphilis by the nested PCR assay. Emerging Microbes \& Infections. May 9;7(1):83. DOI: 10.1038/s41426-018-0085-2. Erratum in: Emerging Microbes \& Infections. 2020 Dec;9(1):1174. PMID: 29739928; PMCID: PMC5940865.

World Health Organization Global adult estimates of chlamydia, gonorrhoea, trichomoniasis and syphilis including maternal and congenital syphilis, 2016, Geneva, WHO; 2020, 76p.

Zhang, Y., Dai, X., Ren, Z., Lin, H., Cao, W., Ye, X. (2019). A Novel Nested Real-time Polymerase Chain Reaction for Treponema pallidum DNA in Syphilis Biospecimens. Sexually Transmited Diseases. Jan;46(1):41-46. DOI: 10.1097/OLQ.0000000000000908. PMID: 30247262. 